\title{
GILBERTO FREYRE E UMA VISÃO TROPICAL DE CAMÕES
}

\author{
Patrícia da Silva Cardoso*
}

escritor Walter Benjamin acreditava que:

quem pretende se aproximar do próprio passado soterrado deve agir como o homem que escava. Antes de tudo, não deve temer voltar sempre ao mesmo fato, espalhá-lo como se espalha a terra, revolvê-lo como se revolve o solo. Pois "fatos" nada são além de camadas que apenas à exploração mais cuidadosa entregam aquilo que recompensa a escavação. Ou seja, as imagens que, desprendidas de todas as conexões mais primitivas, ficam como preciosidades nos sóbrios aposentos de nosso entendimento tardio. ${ }^{1}$

O modo como Benjamin encara o procedimento de todo aquele que se vê diante do fato histórico - através da imagem do arqueólogo - pode ser muito útil para nós, brasileiros, que, de um modo geral, temos sérias dificuldades em lidar

* Universidade Federal do Paraná.

1 BENJAMIN, W. Escavando e recordando. In: Rua de mão única. 2. ed. São Paulo: Brasiliense, 1987. p. 239. 
com o nosso passado coletivo. Talvez como resultado da apropriação pouco legítima de boa parcela de nossas datas históricas por parte de regimes políticos não democráticos, acabamos sempre reagindo de maneira desconfiada - quando não descrente - à idéia da comemoração das chamadas datas nacionais. Somese a esse trauma, o fato de nosso perfil cultural definir-se em boa parte justamente por uma recusa em atribuir qualquer valor positivo ao nosso passado, justificando-se essa recusa com o argumento de que a formação cultural brasileira deu-se fora e abaixo - em termos qualitativos - dos modelos culturais tidos como bem-sucedidos. Acabamos assumindo que nossa inferioridade econômica é fruto desse passado mesquinho, sem glórias verdadeiras, em que degredados e escravos uniram-se a contragosto, dando origem a uma sociedade socialmente injusta e ignorante. Tal justificativa converte-se muitas vezes em um agudo sentimento de inferioridade cultural, responsável, por sua vez, pela eleição de outras culturas como mais adequadas a um projeto de crescimento econômico e social. Daí que atribuímos ao passado nacional a qualidade de mistificação, mas não deixamos de confiar que temos um grande futuro a nossa espera - o que também pode ser a manifestação dessa mistificação contra a qual lutamos.

Essas duas maneiras de recusar nosso passado histórico acabam por nos fazer enxergá-lo como um grande bloco maciço, cujo sentido parece inequivocamente desprezível. É nesse ponto que as palavras de Benjamin tornamse úteis: ao nos recusarmos a olhar para o nosso passado, assumimos que o seu significado, em termos de uma decifração do presente, é mais do que evidente, deixando, assim, de proceder às escavações a que se refere Benjamin, em busca dessas camadas profundas em que encontraremos não os fatos históricos congelados em efemérides nacionais, mas as imagens - construções coletivas das quais cada cidadão participa ativamente - que esses fatos nos sugerem. Só assim poderíamos atingir o sentido, que está longe de ser unívoco, da nossa história coletiva. A validade de substituirmos a recusa do passado pela sua exploração é dada pelo fato de, através dela, termos condições de lidar de forma desimpedida, por exemplo, com esse sentimento de inferioridade cultural que tanto nos exaspera. A exploração/escavação benjaminiana equivale a uma reflexão. Ao contrário do que nossa recusa quer fazer crer, o passado - seja ele coletivo ou individual - jamais pode ser apagado e sua presença no presente é sensível, quer a identifiquemos como comemoração, quer a sintamos como fantasmagoria. Portanto, só refletindo sobre as imagens daqueles que fomos é que poderemos definir quem somos e, já que tanto nos encanta pensar no futuro, quem desejamos ser.

Um bom exemplo da dificuldade que, como coletividade, enfrentamos em trabalhar nosso passado histórico - e, por extensão, em escavar nossas origens 
- foi dado pela Folha de São Paulo quando, a propósito das comemorações em torno dos 500 anos do descobrimento lançou uma enquete cujo título era: "Você vai comemorar os 500 anos?" Uma pergunta significativa, pois remete para a dúvida quanto à propriedade - quiçá legitimidade - de uma disposição para comemorar data que, por motivos que misturam fatores de ordem ideológica com outros, relativos a uma psicologia coletiva, tornam suspeito esse tipo de comemoração. Sem nos determos aqui na discussão da acuidade dessa data na determinação de nossa origem, registremos apenas que há pouco mais de 500 anos iniciou-se um processo que acabou por transformar irremediavelmente a realidade dos que aqui chegaram naquele momento e dos que aqui já estavam, dando origem a uma nova realidade que acabou por ser conhecida como Brasil.

Se houve alguém que se interessou por esse processo de constituição da nacionalidade através de uma série de transformações, esse alguém foi Gilberto Freyre. Em Casa Grande \& Senzala, a obra com que inicia sua escavação no terreno da história cultural brasileira, Freyre parte da constatação de que as relações entre senhores e escravos no Brasil colonial constituíram-se de maneira diferenciada, se comparadas com o que ocorreu na América Espanhola, cujos senhores optaram pela manutenção de um contato o mais distante possível dos elementos não europeus envolvidos no processo colonizador. Para Freyre os portugueses teriam uma predisposição cultural para um contato com índios e negros nada distanciado, acabando por interferir - o que está longe de representar um abalo que a descaracterizasse - na estrutura hierárquica responsável pelo estabelecimento dos papéis de mando e obediência. Tal interferência permitiria um contato íntimo, efetivo, entre essas três culturas, que por sua vez seria responsável pela formação de uma cultura heterogênea na sua constituição, mas indiscutivelmente autônoma em relação às três culturas originais:

Vencedores no sentido militar e técnico sobre as populações indígenas; dominadores absolutos dos negros importados da África para o duro trabalho da bagaceira, os europeus e seus descendentes tiveram entretanto de transigir com índios e negros quanto às relações genéticas e sociais. A escassez de mulheres brancas criou zonas de confraternização entre vencedores e vencidos, entre senhores e escravos. Sem deixarem de ser relações - as dos brancos com as mulheres de cor-de "superiores" com "inferiores" e, no maior número de casos, de senhores desabusados e sádicos com escravas passivas, adoçaram-se, entretanto, com a necessidade experimentada por muitos colonos de constituírem família dentro 
dessas circunstâncias e sobre essa base. A miscigenação que largamente se praticou aqui corrigiu a distância social que doutro modo se teria conservado enorme entre a casa-grande e a mata tropical; entre a casa-grande e a senzala. ${ }^{2}$

Nesse início de escavação já o autor dá mostras de que o terreno não é uniforme e são muitas as camadas de terra a serem retiradas para que se chegue ao objeto desejado: a imagem de passado em que talvez nos sintamos refletidos. Afinal, não se trata de um contato idealizado, sem traumas, sem a pressão da própria hierarquia. Entretanto, há um aspecto positivo desse contato, justamente no que se refere à relativização da relação de oposição entre "superiores" e "inferiores", relativização essa que, segundo Freyre, acabou por se converter em uma democratização social:

Entre os filhos mestiços, legítimos e mesmo ilegítimos, havidos delas [índias e negras] pelos senhores brancos, subdividiu-se parte considerável das grandes propriedades, quebrando-se assim a força das sesmarias feudais e dos latifúndios do tamanho de reinos. ${ }^{3}$

Originando-se em parte de um problema prático - a falta de mulheres brancas na terra - esse tipo particular de contato entre o colonizador português e as duas modalidades de colonizados não teria um resultado tão rápido, no que diz respeito à efetiva miscigenação, se não houvesse, por parte desse colonizador, uma disposição para superar as barreiras erguidas pelas diferenças culturais, diferenças essas que em geral levavam o colonizador a identificar-se como representante de uma cultura superior, que de forma alguma - nem mesmo diante de uma tão grande necessidade - deveria se submeter a tão perigosa aproximação.

Essa disposição encontrada no português - fator de distinção desse colonizador - seria, para Freyre, resultado do prolongado contato anterior desses mesmos portugueses com culturas tão diferentes da européia, como a árabe e a

2 FREYRE, G. Casa Grande \& Senzala. 34. ed. Rio de Janeiro: Record, 1998. p. 1.

3 Id. 
judaica. Os próprios portugueses teriam, na base de sua formação cultural, essa mistura que posteriormente levaram adiante na colonização, não apenas do Brasil, mas também das regiões da África e da Ásia em que se estabeleceram. A origem misturada acabou por funcionar como um elemento importante na abertura para o outro que se observa nos portugueses desde o início de suas aventuras no além-mar. Abertura que fez com que eles identificassem positivamente manifestações culturais radicalmente distintas das experimentadas pelos europeus. Exemplares dessa abertura são a descrição maravilhada da arquitetura árabe feita por Zurara, ao registrar a tomada de Ceuta aos mouros, em 1415:

Grandes casas ladrilhadas com tijolos vidrados de desvairadas cores, e os tetos forrados de olivel [tábuas], com formosas açoteas [mirantes]cercadas de mármores mui alvos e polidos, e as camas brandas e moles e com roupas de desvairados lavores, como vedes que geralmente são as obras dos mouros (...) em comparação destas, [nossas pobres casas] querem parecer choças de porcos. ${ }^{4}$

Também a descrição dos índios brasileiros e de sua arte plumária feita por Caminha poderia ser incluída nessa abertura. Freyre considera esse relativismo antropológico experimentado pelos portugueses - de grande ajuda na sua total adaptação às mais diferentes regiões da terra - um modelo através do qual poderíamos atingir uma democracia verdadeira, cujas bases não estariam em um sistema político, mas na aceitação e convivência de diferentes culturas num mesmo espaço. Esse novo modelo teria sua eficácia assegurada porque neutralizaria a força de uma das bases de boa parte dos movimentos que visam estabelecer um padrão de qualidade racial - que acaba determinando o estabelecimento de um padrão de qualidade socioeconômico - que não é outro senão o da pureza étnica:

Há, diante desse problema de importância cada vez maior para os povos modernos - o da mestiçagem, o das relações de europeus

4 ZURARA, G. E. de. Crónica da tomada de Ceuta. Lisboa: Europa-América, 1992. p. 256-257. 
com pretos, pardos, amarelos - uma atitude distintamente, tipicamente, caracteristicamente portuguesa, ou melhor, lusobrasileira, luso-asiática, luso-africana, que nos torna uma unidade psicológica e de cultura fundada sobre um dos acontecimentos, talvez se possa dizer, sobre uma das soluções humanas de problemas de ordem biológica e ao mesmo tempo social, mais significativas de nosso tempo: a democratização de sociedades humanas através da mistura de raças, do cruzamento, da miscigenação. (...) Democracia social, essencial, humana, quero dizer... ${ }^{5}$

De todos os portugueses, foi Luís de Camões aquele que, para Gilberto Freyre, melhor compreendeu e sistematizou - depois de experimentar pessoalmente - essa curiosidade e disponibilidade para o mundo ainda não catalogado que se apresentou aos olhos europeus ao longo do processo de expansão ultramarina. Em Os Lusíadas Camões iria incorporar o resultado da experiência de observador desse Mundo Novo, sem, no entanto, deixar de registrar o seu envolvimento nesse mundo observado, sua inclusão no diferente, no exótico, cujo resultado seria a ampliação, pela incorporação de inúmeros aspectos de outras culturas, da experiência humana ocidental. Segundo Freyre, Os Lusíadas seriam um poema de aventuras: "E as suas principais aventuras são as do Europeu (...) perdido entre gentes morenas, pretas, pardas amarelas que a sua portuguesíssima capacidade de compreensão do exótico acaba por amar, do mesmo modo que acaba por estimar valores de natureza tropical escandalosamente diferentes dos europeus."

A ampliação da experiência humana seria registrada no épico camoniano através das diversas descrições de natureza, de gente, de costumes que, no poema, têm o objetivo de reforçar a novidade do novo, do ainda não visto e, conseqüentemente, a importância da conquista portuguesa. Exemplar disso seria, segundo Freyre, um trecho como este:

5 FREYRE, G. O mundo que o português criou. Rio de Janeiro: J. Olympio, 1940. p. 49 e 51 .

6 FREYRE, G. Camões, lusista e tropicalista. In: O luso e o trópico. Lisboa: Comissão Executiva das Comemorações do Quinto Centenário da Morte do Infante Dom Henrique, 1961. p. 123. 
Sabei que estais na Índia, onde se estende

Diverso povo, rico e prosperado

De ouro luzente e fina pedraria,

Cheiro suave, ardente especiaria. (Canto VII, 31)

Essas palavras de Monçaide, que recebe os portugueses em sua chegada à Índia, resumem bem o que seria a preocupação camoniana com a apresentação de uma nova experiência de realidade. Ele põe na boca do mouro a caracterização da diferença, mas uma diferença que, em si, nada tem de comprometedor ou negativo, afinal esse diverso povo tem sua diferença registrada tanto em termos de riqueza material - entre eles são abundantes o ouro, as pedras preciosas e as especiarias - quanto em capacidade de excitação dos sentidos, através do odor exalado pelas mesmas especiarias, do qual o próprio povo parece impregnado.

Em um outro trecho do poema vemos a seguinte observação sobre as relações familiares:

Gerais são as mulheres, mas somente

Pera os da geração de seus maridos.

Ditosa condição, ditosa gente,

Que não são de ciúmes ofendidos! (Canto VII, 42)

Diante da informação de que as mulheres eram compartilhadas com todos os familiares do marido, o poeta não resiste a uma comparação com a experiência ocidental que se recusa a ser judicativa ou moralista: os ocidentais estavam impedidos de seguir a mesma prática simplesmente por serem dominados pelo ciúme. Acrescente-se aqui o tom invejoso do registro dessa diferença cultural. A experiência camoniana - representativa da experiência de parte considerável da coletividade portuguesa no período dos descobrimentos - é, segundo acredita Freyre, a expressão de uma simpatia característica da cultura portuguesa, cuja definição corresponderia à capacidade do homem de projetar-se pela imaginação na posição de outro homem e de experimentar - experiência vicária - sentimentos e estados de espírito alheios. Camões em sua obra ativa essa imaginação e nos faz, ainda hoje, experimentar o susto, a maravilha e a eventual grandeza de uma tal empreitada, que nada tem de nacionalismo barato e que não 
diminui em nada o sentimento de contradição que está por trás de qualquer aventura que nos ponha diante da necessidade de rever valores que considerávamos a expressão mais acabada da verdade. Uma revisão tão profunda que, pode-se dizer sem risco de exagero, deve representar, para os europeus daquele momento e para nós leitores pósteros, uma nova criação, não mais de uma perspectiva divina, mas essencialmente humana.

Sobre o processo de miscigenação em que se envolveram os portugueses, Freyre lembra que, ainda que se não possa discordar das observações de estudiosos corajosamente realistas dos processos de nossa formação de que a luxúria e a voluptuosidade tenham tido grande responsabilidade nas uniões inter-raciais, elas não agiram sozinhas:

Sob a obsessão de realismo em que vêm talvez se extremando alguns daqueles críticos, não se deve perder de vista, por medo de romantismo, a ação ou a influência que teve o amor sentimental nas relações de portugueses com as mulheres de cor. (...) $\mathrm{O}$ amor desses homens pelas mulheres índias e mais tarde pelas africanas, amor acima de preconceitos e de convenções, agiu poderosamente na formação do Brasil (...) amolecendo o que o sistema econômico de trabalho escravo prometia levantar ali de hirto, de cruel e desumano. Nunca houve maior vitória do humano, do demasiadamente humano sobre o econômico. ${ }^{7}$

De fato, é assustador para nós, críticos conscientes da desumanidade de base em nossa formação, pensar que um conceito tão fluído, tão carente de realidade como o de amor pudesse definir ou explicar a miscigenação. Talvez -e neste ponto Freyre está inocente, já que é de minha responsabilidade a próxima apropriação - seja num poema do aventureiro Camões que encontremos forças para aceitar que alguma forma de amor tenha ido de mistura com tanto horror e violência. Trata-se do inesquecível Endechas a Bárbara escrava. Se, como quer Freyre, é de relativização de valores e de modelos que se trata a experiência portuguesa no ultramar, cujo fruto é a cultura miscigenada que nós encarnamos, então nenhum exemplo dessa experiência se compara com o que oferece este

7 FREYRE, $O$ mundo que..., p. 45. 
poema, que tem seu centro na inversão. Inversão de expectativas e, portanto, de valores.

Uma escrava de nome Bárbara é senhora de seu senhor. Essa primeira inversão deve-se ao fato de em Bárbara encontrar-se uma beleza que contraria os padrões europeus "Pretos os cabelos, onde o povo vão perde opinião que os louros são belos / Pretidão de Amor, tão doce figura, que a neve lhe jura que trocara a cor". Sua figura negra é doce, tão doce que a única explicação para tamanha maravilha seria a de uma inversão da natureza. Mas não são apenas físicos os atributos dessa cativa-senhora. Ela é séria - talvez contrariando as imagens, comuns na lírica, que apresentam as mulheres belas como caprichosas, voluntariosas. E, por fim, transmite paz a esse homem, neutralizando seu sofrimento e servindo de motivo para seu poema e para sua vida. Como diz Camões, em mais uma inversão, a singularidade de Bárbara pode ser sinal de estranheza - de diferença - mas nunca de barbarismo. A união de qualidades físicas a outras, morais, dá à caracterização de Bárbara uma complexidade que nos impede de vê-la como uma peça da qual, uma vez satisfeito, esse 'eu' lírico se livrará.

Bem menos eufórica em relação à importância desse traço cultural português foi a abordagem de Sérgio Buarque, o companheiro de escavação de Freyre nos anos 30. A tal abertura para o outro, herança legada aos brasileiros pelos colonizadores portugueses, seria, para o autor de Raízes do Brasil, não um fator a serviço do estabelecimento desse traço original em termos de uma solução das nossas contradições culturais, mas um ponto de partida para, justamente, assumirmos que nem sempre as heranças que nos chegam dos antepassados têm utilidade. Assim, visando uma leitura dialética do passado histórico - social e econômico - brasileiro, Sérgio Buarque vai buscar no mesmo Camões elementos que o ajudem a relativizar a grandeza dessa abertura para $o$ outro portuguesa, que, segundo Freyre, estaria embutida no movimento de expansão ultramarina, constituindo o diferencial positivo das conquistas lusitanas. Diz Sérgio Buarque:

Em Camões, a tinta épica de que se esmaltavam os altos feitos lusitanos não corresponde tanto a uma aspiração generosa e ascendente, como a uma retrospecção melancólica de glória 
extintas. Nesse sentido cabe dizer que o poeta contribuiu antes para desfigurar do que para fixar eternamente a verdadeira fisionomia moral dos heróis da expansão ultramarina. ${ }^{8}$

Também no que diz respeito ao registro maravilhado que fazem os portugueses das regiões por que passam Sérgio Buarque fará uma leitura que exclui a identificação de um traço cultural único, que seria usado por Freyre em sua composição da imagem do português:

O deslumbramento que se apodera do navegante em face desses paraísos esquecidos entre mares ignotos, (...) acha-se na origem dos mais velhos e constantes temas poéticos. Temas que, depois de ganhar extraordinária força evocativa, justamente na era dos grandes descobrimentos geográficos, (...) levarão a esse multiforme romantismo insular, cuja marca é visível em obras de autores tão diferentes entre si como São Tomás de Moro e Luís de Camões, por exemplo, ou Luís de Gôngora e Daniel Defoe, cujo fascínio ainda não se dissipou nos nossos dias. ${ }^{9}$

Como se vê, para Sérgio Buarque a capacidade de se encantar com a diversidade - associada nas descrições mencionadas a imagens do paraíso -, que Freyre reputa como índice da tal abertura, não constitui um traço distintivo de caráter cultural simplesmente porque é da ordem da tópica literária. Nessa perspectiva, não há nada mais natural, justamente em um momento que a Europa tem a chance de conhecer tantas formas de paraíso, do que essa abundante exploração de um tópico literário.

Depois de trazidas para a discussão essas observações de Sérgio Buarque, creio que cabe voltar atrás e perguntar como ficam as Endechas nesse novo cenário, que não distingue os portugueses - tampouco Camões - como os portadores inequívocos dessa que, na condição de herança, é apontada por p. 80 .

8 HOLANDA, S. B. de. Raizes do Brasil. 12. ed. Rio de Janeiro: J. Olympio, 1978.

9 HOLANDA, S. B. de. Visão do paraíso. 3. ed. São Paulo: Cia. Editora Nacional, 1977. p. 267. 
Freyre como a maior qualidade no processo de formação da identidade brasileira. As Endechas não podem ser vistas como um registro histórico. Afinal, elas são um poema. Um poema é uma imagem que se congela, mas que, ao congelar-se, não nos impede de escavar para descobrir um sentido que a superfície de suas palavras esconde. Mas acontece que os fatos históricos podem também nos fornecer imagens, imagens que não nos ofereçam o reconhecimento fácil de quem afinal somos, o ready made das efemérides nacionais, mas que nos instiguem e animem na escavação. Não nos esqueçamos que é o próprio Sérgio Buarque quem, depois de muito discutir a herança que nos deixaram os portugueses dirá:

O espírito não é força normativa, salvo onde pode servir à vida social e onde the corresponde. As formas superiores da sociedade devem ser como um contorno congênito a ela e dela inseparável: emergem continuamente das suas necessidades específicas e jamais das escolhas caprichosas. Há, porém, um demônio pérfido e pretensioso, que se ocupa em obscurecer aos nossos olhos estas verdades singelas. Inspirados por ele, os homens se vêem diversos do que são e criam novas preferências e repugnâncias. É raro que sejam das boas. ${ }^{10}$

\section{RESUMO}

Gilberto Freyre identificou, na obra de Camões, um ponto de apoio importante - quase um paradigma - para sua teoria sobre a imagem de homem aberto às diferenças culturais do colonizador português. Segundo Freyre, essa abertura para o outro que caracterizaria o português serviria de elemento fundamental no desenvolvimento da imagem identitária brasileira. A proposta deste texto é recuperar esse paradigma camoniano criado por Freyre para, através dele, repensar as relações de espelhamento e estranhamento entre Brasil e Portugal.

Palavras-chave: Gilberto Freyre, Camões, identidade.

10 HOLANDA, S. B. de. Raizes do Brasil. 12. ed. Rio de Janeiro: J. Olympio, 1978. p. 142 . 


\begin{abstract}
Gilberto Freyre identified in Camões' work a kind of paradigm, a very important element in his theory about the peculiarity of the portuguese colonization process. According to Freyre, portuguese colonization was defined by a remarkable acceptance of foreign cultures, which turned out to influence Brasil's own identity development. This essay's proposal is to regain such paradigm in order to analyse the ambiguous relations between Brasil and Portugal.

Key-words: Gilberto Freyre, Camões, identity.
\end{abstract}

\title{
REFERÊNCIAS
}

BENJAMIN, W. Rua de mão única. 2. ed. São Paulo: Brasiliense, 1987.

FREYRE, G. Casa Grande \& Senzala. 34. ed. Rio de Janeiro: Record, 1998.

. O mundo que o português criou. Rio de Janeiro: J. Olympio, 1940.

. O luso e o trópico. Lisboa: Comissão Executiva das Comemorações do Quinto

Centenário da Morte do Infante Dom Henrique, 1961.

HOLANDA, S. B. de. Raizes do Brasil. 12. ed. Rio de Janeiro: J. Olympio, 1978.

Visão do paraíso. 3. ed. São Paulo: Cia. Editora Nacional, 1977.

ZURARA, G. E. de. Crónica da tomada de Ceuta. Lisboa: Europa-América, 1992. 